\title{
ESTUDO DA EXTRAÇÃO DO ÓLEO DE SEMENTE DE UVA DA VARIEDADE BORDÔ POR PRENSAGEM
}

\section{Maraísa Lopes de Menezes ${ }^{1}$}

\section{Nehemias Curvelo Pereira ${ }^{2}$}

Resumo: O Brasil, com sua economia fortemente baseada na agricultura, contribui para a geração de uma grande quantidade de resíduos resultantes das atividades de processamento. Estes resíduos, por sua vez, representam um grave problema ambiental, pois são descartados diretamente no meio ambiente. Isto também ocorre nas vinícolas, que são as maiores processadoras de uvas no país e consideram as sementes de uva como um rejeito, que geralmente é utilizado para adubação do solo e complemento da ração animal. O óleo de semente de uva é rico em ácido linoleico (18:2n-6) e possui um grande poder antioxidante em decorrência da presença de vitamina $E$ em sua composição. Apresenta a propriedade de diminuir o mau colesterol (LDL) e triacilglicerois, e de aumentar o bom colesterol (HDL), diminuindo os riscos de doenças cardiovasculares. Neste trabalho, foi utilizada a técnica de extração do óleo de semente de uva por prensagem, avaliando-se a influência do tempo de extração e pressão no teor de óleo obtido, sendo a melhor condição de extração determinada pela metodologia de superfície de resposta. Os resultados mostraram que para as sementes de uva da variedade Bordô, o maior teor de óleo $(10,311 \%)$ foi obtido utilizando-se sementes secas na temperatura de $40^{\circ} \mathrm{C}$, submetidas a uma pressão de 18 toneladas e um tempo de extração de 12 horas.

Palavras chave: Resíduo. Extração. Óleo de Semente de Uva. 


\section{INTRODUÇÃO}

Atualmente existe um interesse crescente na exploração dos resíduos gerados pela indústria do vinho, sendo que o principal subproduto da vinificação é o bagaço, constituído pelas cascas e sementes das uvas. Estes subprodutos estão sendo utilizados como ração animal e como adubo nos vinhedos, beneficiando os sistemas agrícolas familiares e permitindo às vinícolas se livrarem de um material poluente. Porém, um destino mais nobre pode ser dado a este resíduo industrial por meio da extração do óleo da semente de uva (ARVANITOYANNIS et al., 2006).

A prensagem é o método mais antigo e popular para se eliminar o óleo de sementes oleaginosas, sendo esta prática utilizada desde as antigas prensas com alavancas para obtenção do azeite de oliva, passando pelas prensas tipo parafuso que começaram a ser utilizadas após a Primeira Guerra Mundial, até as prensas modernas, sendo estas hidráulicas ou contínuas (NIMET, 2009).

O óleo de semente de uva é utilizado na Europa como óleo comestível ou como matéria-prima do setor industrial. Para a indústria alimentícia o mesmo apresenta odor agradável, podendo substituir praticamente todos os óleos vegetais, inclusive o de oliva. Sua digestibilidade $(97,2 \%)$ é maior do que a do óleo de soja (95\%). Sua composição química é apropriada para dietas que visam diminuir os níveis de colesterol no sangue devido ao alto teor de ácidos graxos insaturados e fitosteróis (OLIVEIRA, 2010).

Assim, sabendo-se que os estudos sobre a extração do óleo de sementes de uvas brasileiras são escassos, é necessária uma maior pesquisa nesta área para que este produto seja oferecido ao mercado.

\section{METODOLOGIA}

Para as extrações, as sementes foram previamente secas em secador convectivo de leito fixo nas temperaturas de $30,40,50,60$ e 70 e $80 \stackrel{\circ}{\circ}$ e velocidade do ar de 0,8 $\mathrm{m} / \mathrm{s}$. Posteriormente foram trituradas em um triturador modelo TE-345 por 10 segundos, homogeneizadas e trituradas por mais 10 segundos.

Para a extração do óleo, foi utilizada uma prensa hidráulica Bovenau com capacidade de 30 toneladas e $100 \mathrm{~g}$ de sementes de uva. Os ensaios foram realizados 


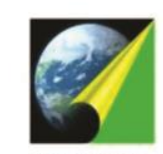

ANAP

em duplicata, sendo as pressões de operação utilizadas de 14, 18 e 22 toneladas. Com relação ao tempo de extração, o frasco contendo o óleo extraído foi pesado em tempos pré-determinados, sendo os tempos totais de 4,8 e 12 horas. Após a extração, foi realizado o cálculo do teor de óleo extraído por meio da razão entre a massa de óleo obtido e a massa de sementes utilizada na prensagem.

As micrografias foram obtidas por meio de microscópio eletrônico de varredura de elétrons Superscan SS - 550 marca Shimadzu, operando com tensão de aceleração de 10 $\mathrm{kV}$, com capacidade de aumento de 60 a 6.000 vezes.

Para a determinação da melhor condição de extração, foi utilizado um planejamento fatorial completo, com todas as possíveis combinações dos níveis dos fatores. As variáveis de entrada (fatores) para a extração por prensagem foram a temperatura de secagem das sementes e o tempo de extração para cada pressão de operação.

\section{RESULTADOS}

A Figura 1 apresenta os teores de óleo obtidos em cada condição de extração para comparação.

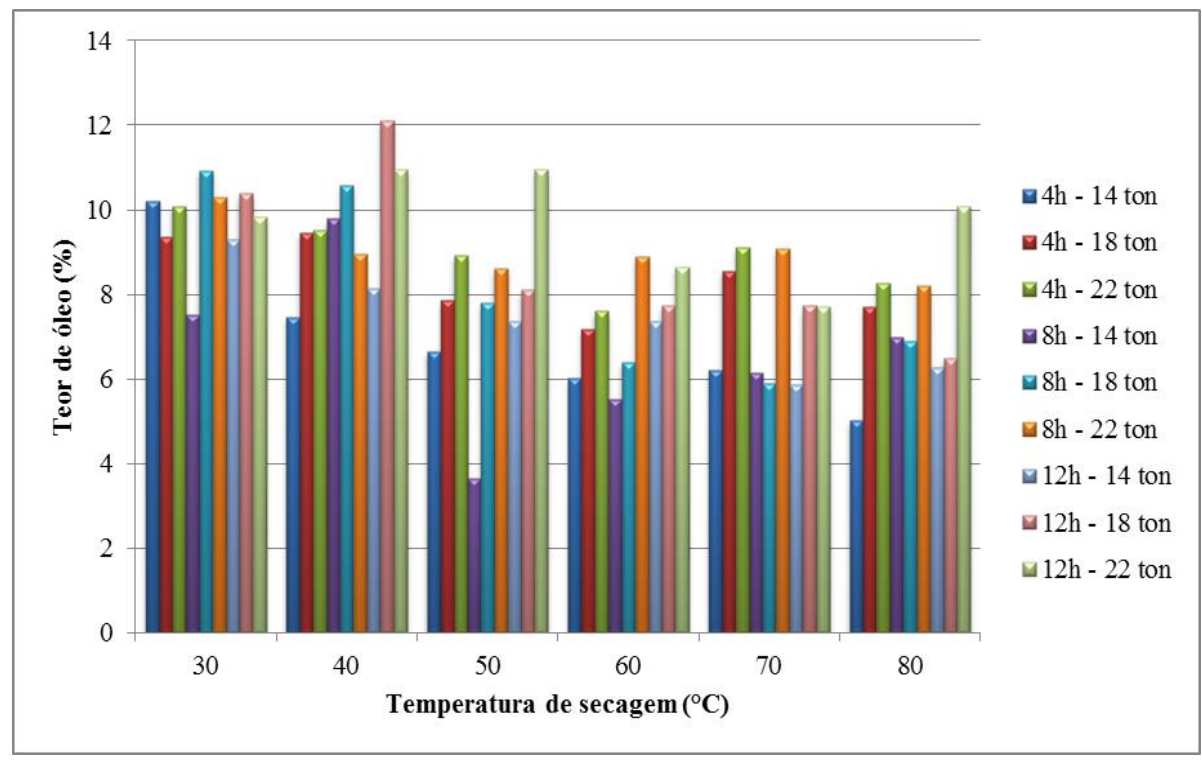

Figura 1: Teor de óleo obtido em cada extração 


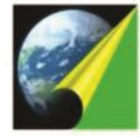

ANAP

Por meio da Figura 1 foi possível verificar que, em altas temperaturas, quanto maior a pressão de operação, maior é o teor de óleo obtido, contudo, em baixas temperaturas foi possível se obter um teor de óleo maior utilizando pressões mais baixas.

Os resultados indicam que a melhor condição de extração por prensagem para as sementes de uva Bordô foi na temperatura de secagem das sementes de $40^{\circ} \mathrm{C}$, utilizando uma pressão de 18 toneladas e um tempo de extração de 12 horas, sendo que tal fenômeno pode ser explicado se for considerado que o aumento da pressão gera uma compactação da torta, o que, por sua vez, diminui os espaços vazios por onde o óleo poderia escoar, dificultando o seu escoamento e diminuindo, assim, o teor de óleo obtido.

Se comparado o teor de óleo obtido com as sementes secas nas temperaturas de 40 e $80^{\circ} \mathrm{C}$, foi obtido um teor de óleo de $7,5 \%$ utilizando uma pressão de 14 toneladas para as sementes secas a $40^{\circ} \mathrm{C}$, enquanto que, para a temperatura de $80^{\circ} \mathrm{C}$, foi necessário utilizar uma pressão de 18 toneladas para se obter este mesmo teor de óleo. Isto mostra uma maior influência da pressão no processo utilizando as sementes secas nas maiores temperaturas e uma menor influência da pressão para as temperaturas de secagem mais baixas $\left(30\right.$ e $\left.40^{\circ} \mathrm{C}\right)$.

A Figura 2 apresenta as micrografias realizadas para as sementes de Bordô secas em diferentes temperaturas, mostrando a influência da temperatura na conformação das fibras das sementes.
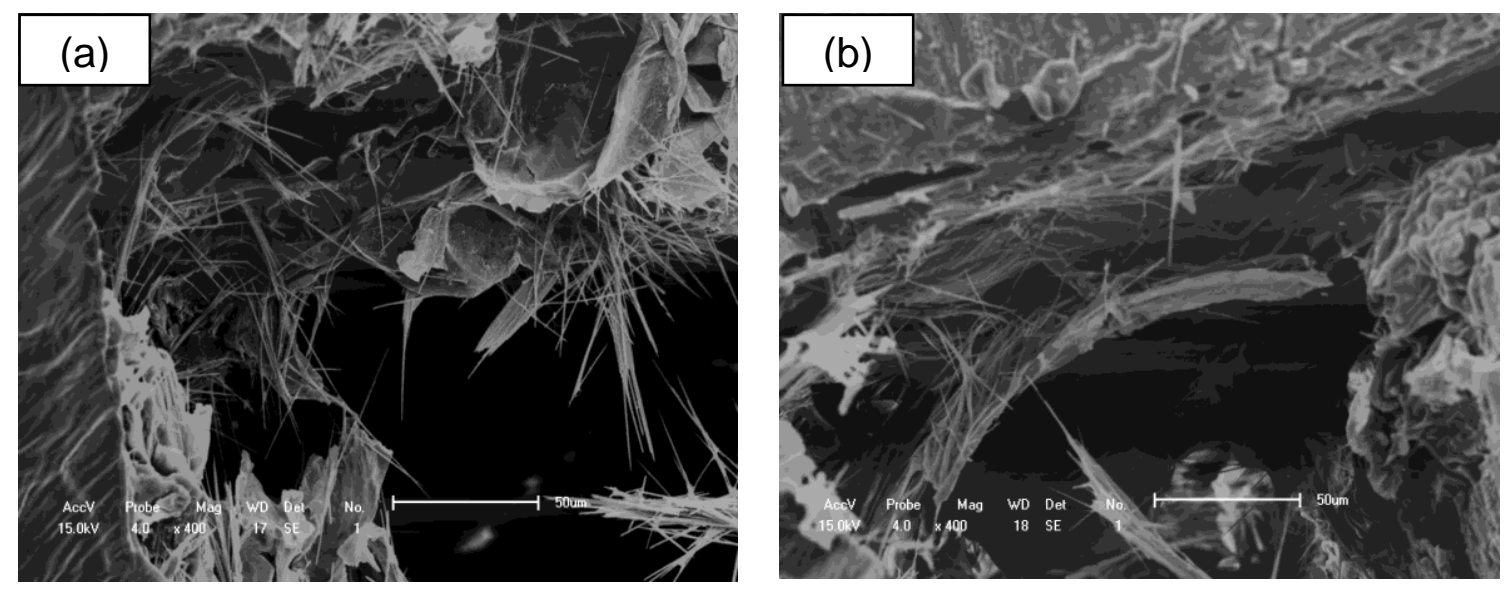

Figura 2: Conformação das fibras das sementes de Bordô secas nas temperaturas de (a) $30^{\circ} \mathrm{C}$ e (b) $105^{\circ} \mathrm{C}$

Por meio da Figura 2 pode-se verificar que para as sementes secas em baixas temperaturas, as fibras aparecem pouco compactadas e conforme se aumenta a 
temperatura de secagem, as fibras passam a apresentar um maior estado de agregação e esta mudança influi diretamente no escoamento do óleo na extração por prensagem, pois em temperaturas de secagem mais altas foi obtido um menor teor de óleo, em todas as condições estudadas. Nas extrações por prensagem, são utilizadas sementes trituradas, mas este procedimento altera a natureza do material e não a natureza das fibras.

As Tabelas 1 a 3 apresentam os resultados obtidos a partir da análise de variância para cada condição de extração.

Tabela 1: Análise de variância para extrações submetidas a pressão de 14 toneladas

\begin{tabular}{c|c|c|c|c|c}
\hline Efeito & $\begin{array}{c}\text { Soma dos } \\
\text { Quadrados }\end{array}$ & $\begin{array}{c}\text { Graus de } \\
\text { liberdade }\end{array}$ & $\begin{array}{c}\text { Soma dos } \\
\text { Quadrados } \\
\text { Médios }\end{array}$ & $\mathrm{F}$ & $\mathrm{p}$-valor \\
\hline Temperatura & 25,71347 & 1 & 25,71347 & 10,30378 & 0,003157 \\
\hline Temperatura $^{2}$ & 17,09040 & 1 & 17,09040 & 6,84572 & 0,013780 \\
\hline Tempo & 0,93994 & 1 & 0,93994 & 0,37650 & 0,544107 \\
\hline Tempo $^{2}$ & 2,06045 & 1 & 2,06045 & 0,82533 & 0,370866 \\
\hline Temperatura*Tempo $^{*}$ & 0,97762 & 1 & 0,97762 & 0,39160 & 0,536194 \\
\hline Erro & 74,89523 & 30 & 2,49651 & &
\end{tabular}

Tabela 2: Análise de variância para extrações submetidas a pressão de 18 toneladas

\begin{tabular}{c|c|c|c|c|c}
\hline Efeito & $\begin{array}{c}\text { Soma dos } \\
\text { Quadrados }\end{array}$ & $\begin{array}{c}\text { Graus de } \\
\text { liberdade }\end{array}$ & $\begin{array}{c}\text { Soma dos } \\
\text { Quadrados } \\
\text { Médios }\end{array}$ & $\mathrm{F}$ & $\mathrm{p}$-valor \\
\hline Temperatura $^{\text {Temperatura }}{ }^{2}$ & 7,60295 & 1 & 7,60295 & 6,17005 & 0,018803 \\
\hline Tempo $_{\text {Tempo }}$ & 5,85566 & 1 & 5,85566 & 4,75207 & 0,037243 \\
\hline Tempo $^{2}$ & 1,11450 & 1 & 0,00055 & 0,00045 & 0,983257 \\
\hline Temperatura*Tempo $^{*}$ & 4,03944 & 1 & 1,11450 & 0,90445 & 0,349190 \\
\hline Erro & 36,96700 & 1 & 4,03944 & 3,27815 & 0,080235 \\
\hline
\end{tabular}

Tabela 3: Análise de variância para extrações submetidas a pressão de 22 toneladas

\begin{tabular}{c|c|c|c|c|c}
\hline Efeito & $\begin{array}{c}\text { Soma dos } \\
\text { Quadrados }\end{array}$ & $\begin{array}{c}\text { Graus de } \\
\text { liberdade }\end{array}$ & $\begin{array}{c}\text { Soma dos } \\
\text { Quadrados } \\
\text { Médios }\end{array}$ & $\mathrm{F}$ & p-valor \\
\hline Temperatura $^{2}$ & 3,61127 & 1 & 3,61127 & 2,56740 & 0,119566 \\
\hline Temperatura $^{2}$ & 1,90894 & 1 & 1,90894 & 1,35714 & 0,253213 \\
\hline Tempo $^{2}$ & 0,82165 & 1 & 0,82165 & 0,58414 & 0,450662 \\
\hline Tempo $^{2}$ & 0,54781 & 1 & 0,54781 & 0,38946 & 0,537300 \\
\hline Temperatura*Tempo $^{*}$ & 0,03546 & 1 & 0,03546 & 0,02521 & 0,874912 \\
\hline Erro & 42,19759 & 30 & 1,40659 & & \\
\hline
\end{tabular}




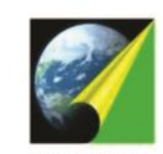

ANAP

A partir das Tabelas 1 a 3 é possível se verificar que em baixas pressões (14 e 18 toneladas) a temperatura de secagem das sementes foi significativa no processo, uma vez que o p-valor é menor que $5 \%$. Diferentemente do tempo de extração, que não foi significativo em nenhuma das condições de extração estudadas.

A Figura 3 apresenta as superfícies de resposta obtidas para cada condição de extração.

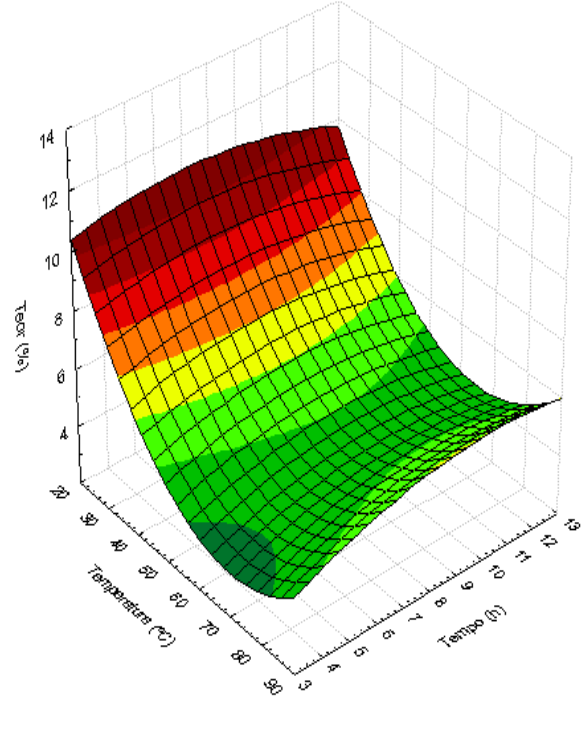

(a)

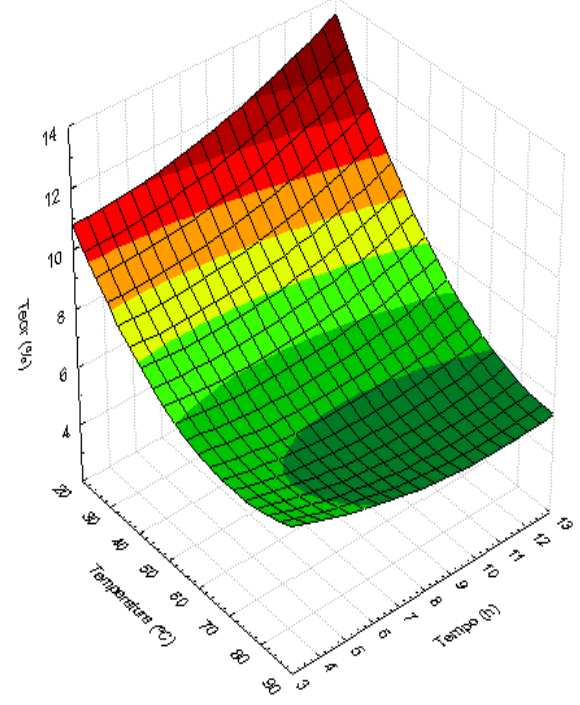

(b)

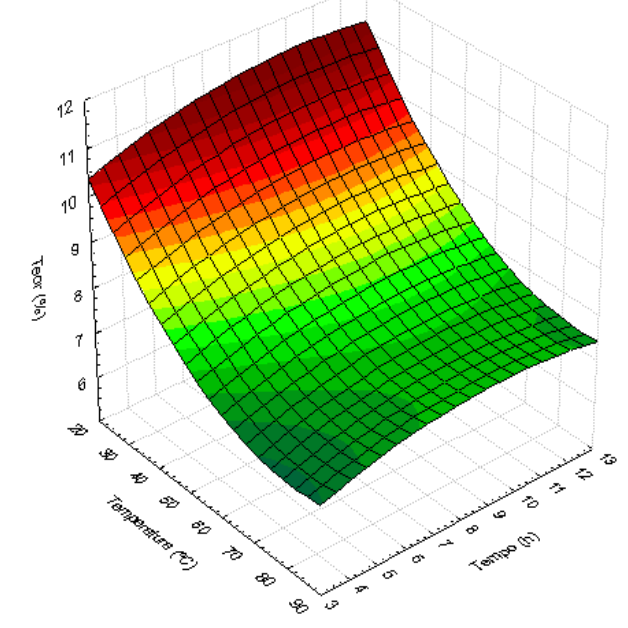

(c)

Figura 3: Superfícies de resposta referentes as extrações do óleo de semente de uva da variedade Bordô: (a) 14, (b) 18 e (c) 22 toneladas 
$\mathrm{Na}$ Figura 3 é possível verificar que o maior teor de óleo foi obtido utilizando sementes secas em baixas temperaturas e submetidas a longos tempos de extração, comprovando o fato de que a diminuição da temperatura de secagem, bem como o aumento do tempo de extração favorece o processo, ou seja, provocam um aumento no teor de óleo obtido.

Desta maneira, a melhor condição para a extração do óleo de semente de uva da variedade Bordô, com base no teor de óleo obtido, foi utilizando sementes secas a $40^{\circ} \mathrm{C}$, tempo de extração de 12 horas e pressão de operação de 18 toneladas.

\section{CONCLUSÕES}

Pelos resultados foi verificado que nas três pressões utilizadas, a quantidade de massa de óleo extraída foi inversamente proporcional à temperatura de secagem, sendo que tal fenômeno pode ser justificado pela influência da temperatura na conformação das fibras das sementes.

\section{REFERÊNCIAS}

ARVANITOYANNIS, I. S.; LADAS, D.; MAVROMATIS, A., Potential uses and applications of treated wine waste: a review. International Journal of Food Science and Technology, Oxford, v. 41, p. 475-487, 2006.

FREITAS, L. S., Desenvolvimento de procedimentos de extração do óleo de semente de uva e caracterização química dos compostos extraídos. Tese (Doutorado), Instituto de Química, Universidade Federal do Rio Grande do Sul, 2007.

NIMET, G., Avaliação dos solventes dióxido de carbono supercrítico e propano subcrítico na extração do óleo essencial de girassol. Dissertação (Mestrado), Universidade Estadual do Oeste do Paraná, 2009. 
OLIVEIRA, D. A., Caracterização fitoquímica e biológica de extratos obtidos de bagaço de uva (Vítis Vinífera) das variedades Merlot e Syrah. Dissertação (Mestrado), Universidade Federal de Santa Catarina, 2010. 